\title{
Distal major pedicle of sartorius muscle flap: Anatomical study and its clinical implications
}

\author{
K. N. Manjunath, M. S. Venkatesh, Ashwini Shivaprasad ${ }^{1}$ \\ Departments of Plastic and Reconstructive Surgery and ${ }^{1}$ Anatomy, Ramaiah Medical College, Bengaluru, Karnataka, India
}

Address for correspondence: Dr. K. N. Manjunath, Department of Plastic and Reconstructive Surgery, RMC, Bengaluru, Karnataka, India. E-mail: drknmanjunath@gmail.com

\section{ABSTRACT}

Background: Reconstruction of the popliteal region has limited option in terms of muscle flaps or myocutaneous flaps. Gastrocnemius muscle or the myocutaneous flaps are the option for majority of cases. However, reach of Gastrocnemius is limited if the wound is on the distal one-third thigh or the lateral aspect of knee region. Similarly, if the wound injures the muscle, then coverage becomes all the more difficult. Although inferiorly based fasciocutaneous flaps can cover the wound in case of bony injuries, muscle flaps are beneficial as they help in fracture healing. However, in cases with direct gastrocnemius muscle injury or if the wound on the distal one-third thigh or the lateral aspect then the options of muscle flaps is limited. An inferiorly based sartorius muscle can be one suitable alternative to cover this region. Aims and Objective: The aim is to devise an inferiorly based sartorius muscle flap for coverage of lower thigh, popliteal and upper one-third leg region. Objectives: (1) To identify the location of distal major (largest diameter) pedicle in cadavers and its clinical application. (2) To determine the arc of rotation with distal major pedicle as pivot point. Methods: Ten Cadavers and 20 sartorius muscle dissected out. Prior silicone injection onto the femoral vessels was done to identify the location of the perforators for the sartorius muscle. The distance of perforators from anterior superior iliac spine (ASIS) measured and the diameter of each perforator by transverse cut measured using callipers. In clinical cases, the arc of rotation was measured by keeping the distal perforator intact as pedicle (detaching the muscle from the ASIS without detaching from the insertion and then rotating it). Results: Out of the 10 cadavers analysed, 6 were male and 4 were female. The mean location of the distal major pedicle was at $35.25 \mathrm{~cm}$ from ASIS and range was between $30.4 \mathrm{~cm}$ to $38.3 \mathrm{~cm}$. There was no significant variation between right and left limbs in individual cadaver (range $0.2 \mathrm{~cm}-1.6 \mathrm{~cm}$ ). The mean diameter of the arterial component of distal major pedicle was $1.54 \mathrm{~mm}$. In three clinical cases where this flap was harvested the arc of rotation were $95^{\circ}, 110^{\circ}, 125^{\circ}$. In one of the cases where flap was used to cover the tibial plateau (arc of rotation $155^{\circ}$ ), distal end of the muscle necrosed. Conclusion: This cadaver study supported by various other studies show that it has sizeable distal pedicle based on which whole muscle

\begin{tabular}{|l|l|}
\hline \multicolumn{2}{|c|}{ Access this article online } \\
\hline Quick Response Code: & Website: \\
\hline
\end{tabular}

This is an open access article distributed under the terms of the Creative Commons Attribution-NonCommercial-ShareAlike 3.0 License, which allows others to remix, tweak, and build upon the work non-commercially, as long as the author is credited and the new creations are licensed under the identical terms.

For reprints contact: reprints@medknow.com

How to cite this article: Manjunath $\mathrm{KN}$, Venkatesh MS, Shivaprasad A. Distal major pedicle of sartorius muscle flap: Anatomical study and its clinical implications. Indian J Plast Surg 2018;51:40-5. 
can be harvested as flap. In our study, the usual location of this pedicle is at $35 \mathrm{~cm}$ from ASIS. The mean diameter of the widest pedicle in distal one-third was $1.54 \mathrm{~mm}$ which along with other small diameter pedicle can support the entire muscle. This flap reached up to the infrapatellar region without any vascular compromise.

\section{KEY WORDS}

Distal major pedicle, muscle flap, sartorius

\section{INTRODUCTION}

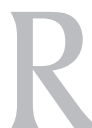

econstruction of soft-tissue loss around the knee and popliteal region is a difficult task. $\cdot^{[1]}$ The reconstructive options are either local fasciocutaneous flaps ${ }^{[2-4]}$ or muscle flaps especially gastrocnemius, ${ }^{[5-8]}$ which is a major muscle flap available for local cover and the microvascular-free flap..$^{[9,10]}$ The sartorius muscle provides an alternative for muscle flap in this region. Sartorius has all the qualities of an ideal donor for flap. ${ }^{[11]}$ It is dispensable highly vascular, long muscle. According to Mathes and Nahai, it is classified as class IV muscle ${ }^{[11]}$ with segmental blood supply. Various studies have shown that $80 \%-90 \%$ of muscle can survive with a single vascular pedicle; either on the proximal or distal. ${ }^{[12-14]}$ It is apparent that larger the diameter of the pedicle, the greater is the chance that it supplies the majority of the muscle. Use of sartorius as proximally based flap for coverage of exposed femoral vessels is well known. ${ }^{[15]}$ Hence, in this study, we analyse the pedicle diameter to identify the largest diameter pedicle in distal one-third of the thigh, its location and also the arc of rotation of the distally based muscle flap with this pedicle as the pivot point when used in clinical application.

\section{METHODS}

Ten Cadavers were selected which had no external scars or previous surgery marks. All were embalmed cadavers only. In all cadavers, bilateral femoral vessels exposed by small incisions and similarly popliteal vessels were exposed and ligated. About $15-20 \mathrm{ml}$ of the liquid dyed silicone was injected into the femoral vessels and allowed to run down. Slight head-up (20-30 head-up) was maintained to provide additional benefit of gravity. After about 6 hours (duration for hardening of silicone), the dissection was done. The sartorius muscle was exposed with a longitudinal incision from anterior superior iliac spine (ASIS) to knee joint line. Under operating loupe magnification, the vascular pedicles of sartorius were identified (as silicone dyes the vessels red it in easier). The muscle was divided into the upper, middle and lower one-third. In the lower one-third, the visibly largest pedicle was identified and termed as distal major pedicle. Its location from ASIS was determined. Then, the diameter of the arterial part of the pedicle was measured at the site of origin from the superficial femoral artery. Since the liquid silicone injected hardens, measurement of the diameter becomes easier as vessels were filled with hard silicone. After identification of the pedicle the muscle was detached from origin and all pedicles proximal to the identified Pedicle were cut. Then, muscle was rotated with distal major pedicle as pivot point to know the distal reach of muscle. In clinical cases, the pedicles distal to the identified distal major pedicle were kept intact to reinforce the vascularity of the muscle. However, the arc of rotation was measured with the identified distal major pedicle as pivot point.

\section{RESULTS}

Out of the 10 cadavers analysed, 6 were male and 4 were female. The mean location of the distal major pedicle was at $35.25 \mathrm{~cm}$ from ASIS and range was between $30.4 \mathrm{~cm}$ to $38.3 \mathrm{~cm}$ [Picture. 1]. There was no significant variation between right and left limbs in individual cadaver (range $0.2-1.6 \mathrm{~cm}$ ). No dexterity was maintained to opine that one side has pedicle higher or lower than the other side. The mean diameter of the arterial component of

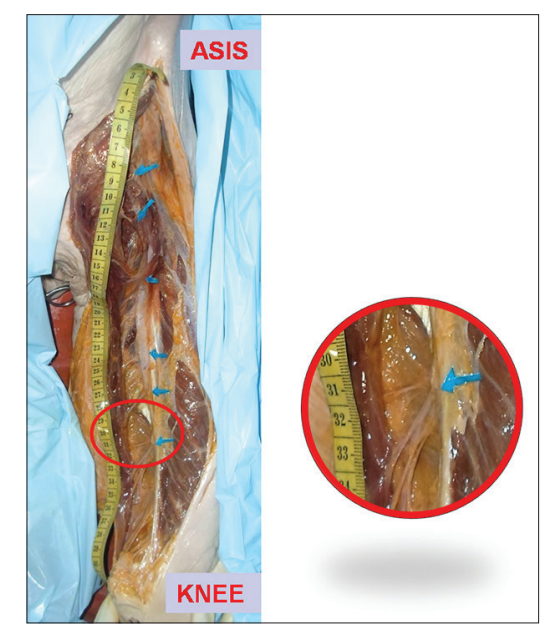

Picture 1: Cadaver study showing all pedicles along with distal major pedicle at $32.2 \mathrm{~cm}$ 
distal major pedicle was $1.54 \mathrm{~mm}$ [Table. 1]. The range was 1.4-1.8 mm. In cadavers, the Arc of rotation was not measured. However, in clinical cases, the distal reach of the muscle, with distal major pedicle, was till the infrapatellar region.

\section{Clinical cases}

In four clinical cases where this flap was used, the arc of rotation was $95^{\circ}, 110^{\circ}, 125^{\circ}$. One of the cases where flap was used to cover the tibial plateau, distal end of the muscle necrosed [Table 2].

\section{Case 1}

The patient had post-traumatic fracture of the lower one-third of femur with wound on the lateral aspect of knee [Picture 2]. Fracture was fixed with ring external fixator and wound

Table 1: Cadaver anatomical characteristics

\begin{tabular}{|c|c|c|c|}
\hline Cadaver sex & $\begin{array}{l}\text { Cadaver } \\
\text { number }\end{array}$ & $\begin{array}{l}\text { Distance of distal } \\
\text { major pedicle from } \\
\text { ASIS (cm) }\end{array}$ & $\begin{array}{l}\text { Diameter of } \\
\text { distal major } \\
\text { pedicle }(\mathrm{mm})\end{array}$ \\
\hline \multirow[t]{2}{*}{ Female } & 1 right & 34.9 & \\
\hline & $1 \mathrm{left}$ & 35.4 & 1.4 \\
\hline \multirow[t]{2}{*}{ Male } & 2 right & 36.2 & \\
\hline & 2 left & 37 & 1.5 \\
\hline \multirow[t]{2}{*}{ Male } & 3 right & 35 & \\
\hline & 3 left & 35.5 & 1.7 \\
\hline \multirow[t]{2}{*}{ Male } & 4 right & 38.3 & \\
\hline & 4 left & 38 & 1.7 \\
\hline \multirow[t]{2}{*}{ Female } & 5 right & 30.6 & \\
\hline & 5 left & 30.4 & 1.4 \\
\hline \multirow[t]{2}{*}{ Male } & 6 right & $32.2^{*}$ & \\
\hline & 6 left & 32.8 & 1.4 \\
\hline \multirow[t]{2}{*}{ Male } & 7 right & 36.5 & \\
\hline & $7 \mathrm{left}$ & 38.1 & 1.6 \\
\hline \multirow[t]{2}{*}{ Female } & 8 right & 34.9 & \\
\hline & 8 left & 35.3 & 1.6 \\
\hline \multirow[t]{2}{*}{ Female } & 9 right & 34.8 & \\
\hline & 9 left & 33.3 & 1.4 \\
\hline \multirow[t]{2}{*}{ Male } & 10 right & 38.1 & \\
\hline & 10 left & 37.8 & 1.7 \\
\hline 6 male, 4 female & Average & 35.25 & 1.54 \\
\hline
\end{tabular}

Table 2: Clinical cases indicating pedicle location and arc of

\begin{tabular}{lccl}
\hline Indication & $\begin{array}{c}\text { Pedicle } \\
\text { distance } \\
\text { from ASIS } \\
(\mathbf{c m})\end{array}$ & $\begin{array}{c}\text { Arc of } \\
\text { rotation } \\
\left(\mathbf{(}^{\circ}\right.\end{array}$ & $\begin{array}{l}\text { Flap } \\
\text { outcome }\end{array}$ \\
\hline $\begin{array}{l}\text { Chronic non healing ulcer knee) } \\
\text { Post-traumatic lateral knee }\end{array}$ & 35.8 & 110 & Healthy \\
defect & 34 & 95 & Healthy \\
$\begin{array}{l}\text { Exposed suprapatellar tendon } \\
\text { Exposed tibial plateau }\end{array}$ & 36.2 & 125 & $\begin{array}{l}\text { Healthy } \\
\text { Necrosed } \\
\text { distal end }\end{array}$ \\
\hline
\end{tabular}

ASIS: Anterior superior iliac spine closed primarily. However, the sutures gaped and there was necrosis of the skin. Finally, ulcer of about $4 \mathrm{~cm} \times 4 \mathrm{~cm}$ remained, but it was bone deep with discharging sinus. The sinus was plugged with inferiorly based sartorius muscle flap and skin grafting. Ulcer healed and also the discharge from the bone reduced and bony union occurred within 4 weeks [Picture. 3 shows the arc of rotation].

\section{Case 2}

Post-traumatic wound over the knee with exposed suprapatellar tendon. Inferiorly based sartorius flap done to cover the tendon and joint region. Arc of rotation, in this case, was $125^{\circ}$ [Picture4a. 4b. 4c].

\section{Case 3}

The patient had chronic ulcer over the lateral knee region. This was previously operated case for post-traumatic ulcer with skin graft. The patient had ulcer following skin graft break down which failed to heel for 2 years. After malignancy was ruled out, inferiorly based sartorius muscle flap was done to cover the defect following excision of chronic ulcer.

\section{Case 4}

The patient had post-electrical burn necrosis of the skin over the tibial plateau. Since it was the area of contact, the gastrocnemius was unsuitable because of partial necrosis. Therefore, inferiorly based sartorius flap was used (arc of rotation was $155^{\circ}$ ). However, the distal end necrosed. Probably, extensive rotation stretched the pedicle causing ischaemia. Later, the wound was covered with cross leg flap.

\section{DISCUSSION}

The efficiency of gastrocnemius flap to cover the knee region is proved beyond doubt. However, in injuries of knee

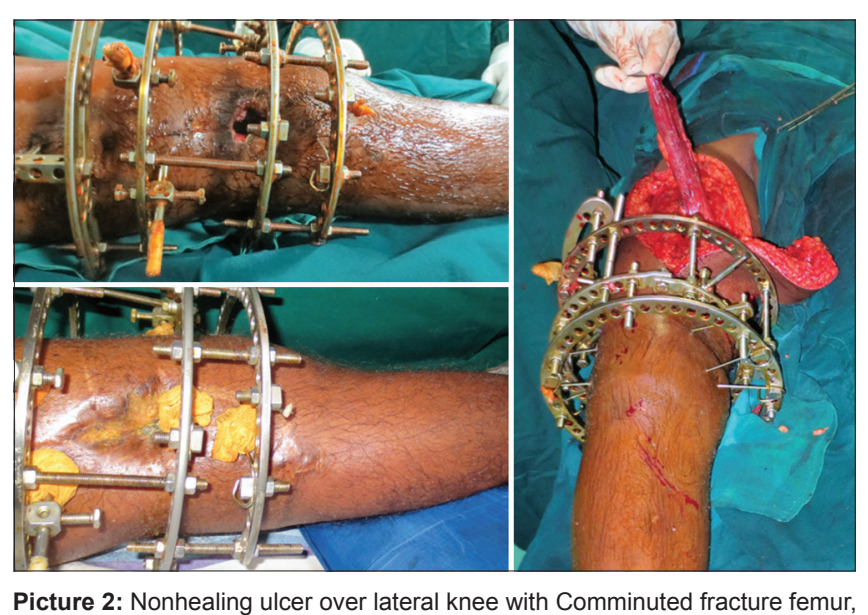
covered with sartorius flap and skin graft 


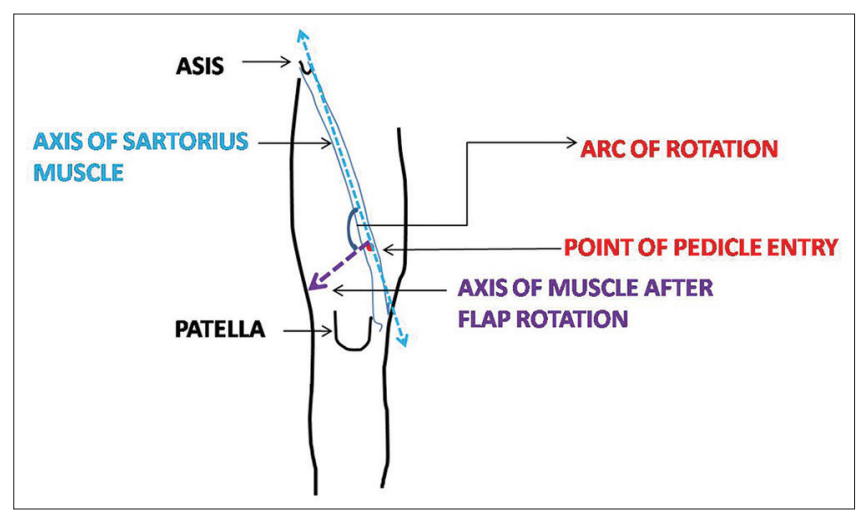

Picture 3: Diagram showing the arc of rotation measurement

region, the vascularity of Gastrocnemius muscle may be affected and it may be unsuitable. ${ }^{[1]}$ Distally based sartorius muscle flap is an effective alternative in such situation.

Sartorius is one of muscles having multiple pedicles. It is also described that each of the pedicles supply roughly the same amount of muscle and they commented that generally such muscles are of less useful in reconstruction than the single or double pedicled muscles. ${ }^{[16]}$ The phenomenon of delay is well known to increase the vascularity in adjacent arteriosome. In muscle flaps, it is the intramuscular anastomosis between the two pedicles which determines the viability of the muscle. The phenomenon of delay to increase the amount of muscle supplied by individual pedicle was studied by Buckland et al. ${ }^{[17,18]}$ and Callegari et al. ${ }^{[19]}$ Hong et al..$^{[1]} \mathrm{JP}$ used this delay phenomenon to increase both muscle and myocutaneous flap over the sartorius muscle to cover these difficult wounds around the knee joint. This was in contrast to the belief that a single arterial pedicle is small to supply entire sartorius muscle. ${ }^{[16]}$ Various anatomical studies done by Kaiser et al. ${ }^{[20]}$ and Habermeyer et al. ${ }^{[12]}$ concluded that majority $(80 \%-90 \%)$ of sartorius muscle can be harvested based on either proximal or distal pedicle alone. The use of proximally based muscle flap on single major pedicle has been already proved clinically. ${ }^{[12]}$ Its use for coverage of exposed femoral vessels or after infection of groin with prosthetic vessels has been published. ${ }^{[13,21-27]}$ However, its use as distally based flap needs to be explored.

The vascular supply of the sartorius muscle has been well-defined. For the purpose of vascular anatomy, we divide the muscle into equal parts (Proximal, Middle and Distal one-thirds). The proximal of one-third receives supply (pedicles) from circumflex femoral and superficial femoral, middle one-third by superficial femoral vessels
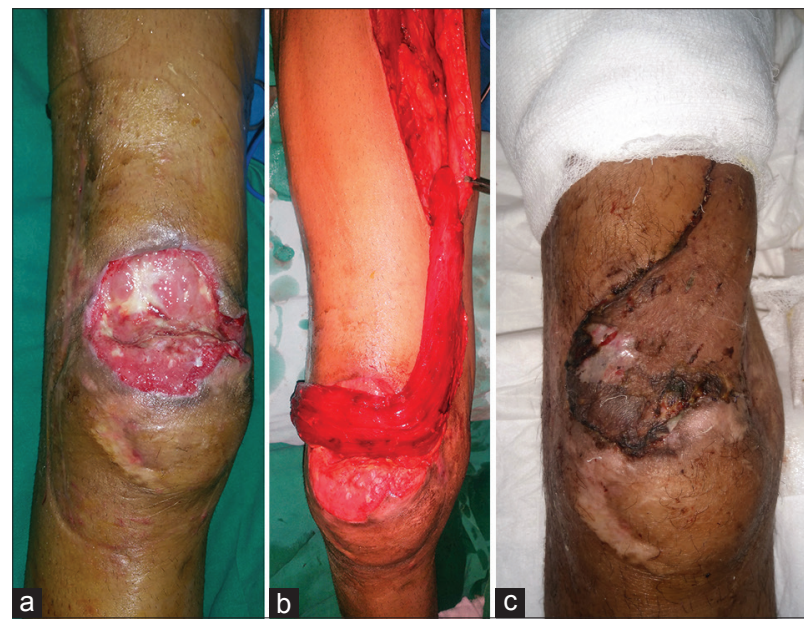

Picture 4: (a) Post-traumatic defect over knee exposing suprapatellar tendon. (b) Sartorius muscle based on distal pedicle placed before in setting. (c) After wound healing

and distal one-third by superficial femoral as well as descending genicular artery branches. ${ }^{[28]}$ We aimed our study for the distal one-third pedicles which arise from superficial femoral as the major pedicle (defined as the largest outer diameter after liquid silicone injection). It is obvious that greater the diameter, greater will be its contribution to muscle survival.

\section{Location}

In our study, the distal major pedicle was located at $35.25 \mathrm{~cm}$ from ASIS. The location of the similar pedicle was between 33.6 and $43.2 \mathrm{~cm}$ in a study done by Mojallal et al. ${ }^{[14]}$ Clavert et al. studied the location of distal major pedicle from the pes anserinus (i.e., from the sartorius insertion site). He identified similar pedicle at $10 \mathrm{~cm}$ from the sartorious insertion. ${ }^{[29]}$ The study group had mean muscle length of $52.16 \mathrm{~cm}$. Considering this muscle length, the distal major pedicle was positioned at $42.16 \mathrm{~cm}$ from ASIS in this study group. Compared to our study group where it was positioned at $35.5 \mathrm{~cm}$, the pedicle in that study group was positioned far caudal. Since the study was done in France, the cadaver built and muscle length definitely had bearing on the position of pedicle. Shorter stature in the South Indian community where our study was contemplated influenced the position of the distal major pedicle. In each limb position of the pedicle (distal major) differed from the other limb. The position varied by $0.2-1.6 \mathrm{~cm}$ i.e., average distance varied by $0.7 \mathrm{~cm}$ which was less significant.

\section{The diameter}

The mean diameter of the arterial component of distal major pedicle was $1.54 \mathrm{~mm}$. The other studies also show 
similar findings, diameter. In a study by Ali Mojjalal average diameter was $1.97 \pm 0.2 \mathrm{~mm}$. Clavert $\mathrm{P}$ et al. ${ }^{[29]}$ showed that diameter of largest pedicle in distal $1 / 3^{\text {rd }}$ was $2.1 \mathrm{~mm}$. Compared to these studies in our study the diameter was less. The reason for this can only be the physical characteristics of the muscle which is influenced by the physical stature of the individual.

\section{Arc of rotation}

Since sartorius is a long muscle, when based on distal one-third pedicles, it covered up to knee and tibial plateau. It rotated more than $110^{\circ}$ with distal major pedicle as pivot point. If more distal smaller pedicles were cut and muscle was propelled on the single major distal pedicle, then it would have rotated more. But when clinically distally based sartorius flap was used we always preserved the distal minor pedicles to supplement the blood supply. Other studies also showed similar results. ${ }^{[30]}$ Buckland et al. ${ }^{[17]}$ suggested that inferiorly based muscle reached almost mid tibial region. In one of our cases, where sartorius was used to cover the exposed tibial plateau, (i.e., rotating muscle at $155^{\circ}$ ) even with distal pedicles intact, the working end necrosed. Other three cases where sartorius rotated for coverage of knee defects (i.e., arch of rotation $110^{\circ} / 125^{\circ} / 95^{\circ}$ ) had no untoward results. Hence, it can be inferred that up to knee region this muscle based on distal pedicle can be safely arced.

\section{CONCLUSION}

Sartorius is known for its segmental blood supply. Our cadaver study shows that it has a sizeable vascular pedicle in the distal one-third (located around $35 \mathrm{~cm}$ from ASIS). Based on this distal major pedicle supplemented with the other minor pedicles, whole of the muscle can be harvested as inferiorly based muscle flap. This flap reached up to the infrapatellar region (arced up to $130^{\circ}$ ) safely. More clinical application of this flap can further authenticate the present cadaver study.

\section{Acknowledgement}

We would like to thank; Dr.Naresh Shetty-Chief Dr. Sundaresh-Past President RamaiahAdvanced Learning Centre. Bengaluru.

\section{Financial support and sponsorship}

Nil.

\section{Conflicts of interest}

There are no conflicts of interest.

\section{REFERENCES}

1. Hong JP, Lee HB, Chung YK, Kim SW, Tark KC. Coverage of difficult wounds around the knee joint with prefabricated, distally based sartorius muscle flaps. Ann Plast Surg 2003;50:484-90.

2. Shaw AD, Ghosh SJ, Quaba AA. The island posterior calf fasciocutaneous flap: An alternative to the gastrocnemius muscle for cover of knee and tibial defects. Plast Reconstr Surg 1998;101:1529-36.

3. Pontén B. The fasciocutaneous flap: Its use in soft tissue defects of the lower leg. Br J Plast Surg 1981;34:215-20.

4. Satoh K, Fukuya F, Matsui A, Onizuka T. Lower leg reconstruction using a sural fasciocutaneous flap. Ann Plast Surg 1989;23:97-103.

5. McCraw JB, Fishman JH, Sharzer LA. The versatile gastrocnemius myocutaneous flap. Plast Reconstr Surg 1978;62:15-23.

6. Sanders R, O'Neill T. The gastrocnemius myocutaneous flap used as a cover for the exposed knee prosthesis. J Bone Joint Surg $\mathrm{Br}$ 1981;63B: 383-6.

7. Elsahy NI. Cover of the exposed knee joint by the lateral head of the gastrocnemius. Br J Plast Surg 1978;31:136-7.

8. Barfod B, Pers M. Gastrocnemius-plasty for primary closure of compound injuries of the knee. J Bone Joint Surg $\mathrm{Br}$ 1970;52:124-7.

9. Feldman JJ, Cohen BE, May JW Jr. The medial gastrocnemius myocutaneous flap. Plast Reconstr Surg 1978;61:531-9.

10. Arnold PG, Prunes-Carrillo F. Vastus medialis muscle flap for functional closure of the exposed knee joint. Plast Reconstr Surg 1981;68:69-72.

11. Mathes SJ, Nahai F. Classification of the vascular anatomy of muscles: Experimental and clinical correlation. Plast Reconstr Surg 1981;67:177-87.

12. Habermeyer $P$, Kaiser E, Mandelkow $H$, Schweiberer L, Stock W. Anatomy and clinical aspects of sartoriusplasty. Handchir Mikrochir Plast Chir 1987;19:21-2.

13. Kaufman JL, Shah DM, Corson JD, Skudder PA, Leather RP. Sartorius muscle coverage for the treatment of complicated vascular surgical wounds. J Cardiovasc Surg (Torino) 1989;30:479-83.

14. Mojallal A, Wong C, Shipkov C, Ho Quoc C, Recchiuto J, Brown S, et al. Redefining the vascular anatomy and clinical applications of the sartorius muscle and myocutaneous flap. Plast Reconstr Surg 2011;127:1946-57.

15. Soyka P, Favez C, Ganzoni N. Treatment of an infected inguinal wound following vascular reconstruction with a sartorius muscle flap. Helv Chir Acta 1990;57:355-8.

16. Cormack GC, Lamberty BG. The Arterial Anatomy of Skin Flaps. Ch. 4. Edinburg Churchill Livingstone; 1986 p. 85.

17. Buckland A, Pan WR, Dhar S, Edwards G, Rozen WM, Ashton MW, et al. Neurovascular anatomy of sartorius muscle flaps: Implications for local transposition and facial reanimation. Plast Reconstr Surg 2009;123:44-54.

18. Petty CT, Hogue RJ Jr. Closure of an exposed knee joint by use of a sartorius muscle flap: Case report. Plast Reconstr Surg 1978;62:458-61.

19. Callegari PR, Taylor GI, Caddy CM, Minabe T. An anatomic review of the delay phenomenon: I. Experimental studies. Plast Reconstr Surg 1992;89:397-407.

20. Kaiser E, Genz KS, Habermeyer P, Mandelkow H. Arterial supply of the sartorius muscle. Chirurg 1984;55:731-2.

21. Khalil IM, Sudarsky L. Sartorius muscle "twist" rotation flap: An answer to flap necrosis. J Vasc Surg 1987;6:93-4.

22. Meland NB, Arnold PG, Pairolero PC, Lovich SF. Muscle-flap 
coverage for infected peripheral vascular prostheses. Plast Reconstr Surg 1994;93:1005-11.

23. Méndez Fernández MA, Quast DC, Geis RC, Henly WS. Distally based sartorius muscle flap in the treatment of infected femoral arterial prostheses. J Cardiovasc Surg (Torino) 1980;21:628-31.

24. Meyer JP, Durham JR, Schwarcz TH, Sawchuk AP, Schuler JJ. The use of sartorius muscle rotation-transfer in the management of wound complications after infrainguinal vein bypass: A report of eight cases and description of the technique. J Vasc Surg 1989;9:731-5.

25. Perez-Burkhardt JL, Gonzalez-Fajardo JA, Carpintero LA, Mateo AM. Sartorius myoplasty for the treatment of infected groins with vascular grafts. J Cardiovasc Surg (Torino) 1995;36:581-5.

26. Perler BA, Vander Kolk CA, Dufresne CR, Williams GM. Can infected prosthetic grafts be salvaged with rotational muscle flaps? Surgery 1991;110:30-4.
27. Soots G, Mikati A, Warembourg H Jr., Watel A, Noblet D. Treatment of lymphorrhea with exposed or infected vascular prosthetic grafts in the groin using sartorius myoplasty. J Cardiovasc Surg (Torino) 1988;29:42-5.

28. Yang D, Morris SF, Sigurdson L. The sartorius muscle: Anatomic considerations for reconstructive surgeons. Surg Radiol Anat 1998;20:307-10.

29. Clavert P, Cognet JM, Baley S, Stussi D, Prevost P, Babin SR, et al. Anatomical basis for distal sartorius muscle flap for reconstructive surgery below the knee. Anatomical study and case report. J Plast Reconstr Aesthet Surg 2008;61:50-4.

30. Manushakian HS, McDiarmid JG. Reconstruction of a large anterolateral knee defect using a delayed distally based total sartorius flap and a medial gastrocnemius flap. Plast Reconstr Surg 1998;101:1065-9. 